\title{
Analysis of the correlation between the Gross Domestic Product and the final consumption of electricity
}

\author{
Liviu Valentin VLĂDUCU \\ School of Advanced Studies of the Romanian Academy (SCOSAAR), Romanian Academy, \\ Bucharest, Romania \\ liviu_vladucu@yahoo.com
}

\begin{abstract}
While the economy has shown clear signs of recovery, in quantitative terms, after the moment of the global crisis, energy production has returned to the level before the crisis, only since 2011. In this context, this paperwork aims to carry out an analysis on the existence of a correlation between the Gross Domestic Product registered in Romania and the final annual consumption of electricity. The databases used involve the data recorded for the period 2000-2018. Over time, in the specialty literature, there have been two approaches regarding the link between the economic growth and the energy consumption, respectively an approach starts from the idea that in order for economic growth to occur, energy consumption must increase, and another promotes the idea that economic growth can reduce energy consumption, by applying energy efficiency measures. To perform the analysis, a simple linear regression model was initially used in which we considered the Gross Domestic Product as a dependent variable and the Electricity Consumption as an explanatory factor (independent variable). Subsequently, analysing the results, a quadratic linear regression model was used to test the hypothesis of a more complex link between the two indicators. Following the tests performed on the two chosen variables, the Gross Domestic Product of Romania and the Final Electricity Consumption, can be argued that the energy intensity of the economy increases as economic growth reaches a certain threshold. After that threshold, economic growth is associated with the relative decrease in energy consumption.
\end{abstract}

Keywords: Energy consumption, GDP, econometric analysis, correlations

\section{Introduction}

After the moment of the global crisis, even though the economy has given quantitative signals of recovery, the energy production returned to the levels as they were before crisis, only after 2011. However, there are two sectors that have had a significant growth in recent years: the wind sector that increased from only $0.3 \mathrm{TWh}$ in 2010 to $7.4 \mathrm{TWh}$ in 2017 and nuclear that is doubled in the last decade. (www.bp.com)

Parallel monitoring of Gross Domestic Product evolution and energy consumption may be relevant in terms of the potential for decoupling between economic growth and environmental impact. This can inspire sound strategies for long-term sustainability.

Therefore, the adoption of measures to increase energy efficiency, the implementation of investment projects for the production of energy from renewable sources, the reduction of consumption shows that, the direct link between economic growth and consumption growth is not a given.

Global issues - such as climate change or poverty reduction, clean energy or quality of life - require a dramatic change in our life and a transformation of the mentality and action directions. (Bratianu \& Vatamanescu, 2017; Dima, A.M., Meghișan-Toma, G.M., 2018; Tantau \& Gavrilescu, 2019).

From the point of view of the resources usage, the gross domestic product is calculated as the sum of the final consumption of the population households, the final consumption of the public and private administration, the gross fixed capital and the trade balance. (Dobrescu, 2002). 
The objective of this study is to carry out an analysis over the existence of a correlation between the Gross Domestic Product registered in Romania and the final electricity consumption, for the period of time, between 2000-2018, in order to determine the degree to which the energy consumption influences the GDP growth. In the following chapters there are shown the relevant aspects regarding dedicated literature, the methodology used and the results obtained, so, in the last section to be revealed the conclusions and future directions of research that result from the study.

\section{Literature review}

Over time, in the dedicated literature, two approaches have emerged regarding the relationship between economic growth and energy consumption, respectively, on the one side, the idea that energy consumption must grow up in order to have an economic growth, and, on the other side, the idea that economic growth can lead to a decrease in energy consumption through the fast implementation of a specific measures for energy efficiency.

Thus, the relationship between the two variables indicates an increase in GDP as an effect of increasing energy consumption, and energy efficiency programs have a negative effect on development, regardless of the time period in which they are implemented (Lee, 2005).

A more recent study shows that, for short period of time, the relationship between energy consumption and economic growth starts from energy, and, for long period of time, the level of economic development is the one that determines the energy consumption (Lau, et al., 2012).

Since 2011, the United Nations has published a report promoting the concept that economic growth can lead to the reducing of the energy consumption, linking it to innovation and the need to rethink the economic progress. (see ww.unep.org)

Thus, there are not the same perspective in Romania. Transelectrica expects that the electricity consumption to be almost doubled by 2030, in the most "unfavorable" scenario, it should only increase with $20 \%$. (www.transelectrica.ro)

Pîrlogea and Ciucea (2011) examine whether there is a relationship between economic growth and energy consumption at present and in different time horizons. They use the energy consumption on various types of fuel, per capita, and real GDP per capita. They believe that the long-term causality only occurs between GDP and energy consumption if the energy will come from hydropower, while the relationship is not valid for the short term.

In the analysis of the current stage, the starting point in the elaboration of the National Energy Strategy (February 2016), the Ministry of Energy recognizes that the decoupling between the evolution of the GDP and the energy consumption has took place in Romania since 2009.

From the analysis carried out for the period 1994-2016, at the level of the EU states, has been confirmed the very high correlation between energy consumption and GDP for the countries in transition and at the level of the developed countries it was concluded that there is no correlation between these variables, most probably because these countries have reached a level of development where energy consumption has no major impact on GDP. (Stjepanović, S., 2018)

Compared to developed countries, Romania has a very high potential for reducing consumption. Energy intensity is twotimes higher than the European average, and sectors such as buildings or transportation could become much more efficient. In addition, the targets for reducing the greenhouse gas emissions have been very small in the context of the Europe 2020 Strategy, being already achieved to a large extent without significant efforts. Although the decoupling of the two indicators can be done in the future in Romania without any measures to encourage it, no measures have been taken to adapt to the new context. For this reason, measures 
that lead to both, economic prosperity and lower energy consumption, must have as a starting point the increase of energy efficiency, the reduction of the emissions generated in the energy sector or the renewable energies development.

\section{Methodology}

In order to analyze this correlation, there was used a simple linear regression model, in which the Gross Domestic Product was considered as a dependent variable and the Electricity consumption as an explanatory factor (independent variable), based on the following series of series (Table 1).

Table 1: Evolution of Gross Domestic Product and Final Electricity Consumption during 2000-2018

\begin{tabular}{|c|c|c|}
\hline Year & $\begin{array}{c}\text { Gross Domestic Product } \\
\text { GDP (milions of eur) }\end{array}$ & The electricity consumption (GWh) \\
\hline 2000 & $40,796.76$ & $32,753.0$ \\
\hline 2001 & $45,503.46$ & $36,294.0$ \\
\hline 2002 & $48,810.36$ & $35,569.0$ \\
\hline 2003 & $52,930.97$ & $37,501.0$ \\
\hline 2004 & $61,404.00$ & $38,774.0$ \\
\hline 2005 & $80,225.58$ & $38,858.0$ \\
\hline 2006 & $98,418.60$ & $40,965.0$ \\
\hline 2007 & $127,632.03$ & $40,949.0$ \\
\hline 2008 & $146,590.62$ & $41,775.0$ \\
\hline 2009 & $125,213.90$ & $37,605.0$ \\
\hline 2010 & $125,408.81$ & $41,317.0$ \\
\hline 2011 & $131,925.36$ & $42,714.0$ \\
\hline 2012 & $133,147.11$ & $42,384.0$ \\
\hline 2013 & $143,801.63$ & $40,627.0$ \\
\hline 2014 & $150,457.97$ & $41,909.0$ \\
\hline 2015 & $160,297.79$ & $43,027.0$ \\
\hline 2016 & $170,393.60$ & $43,258.0$ \\
\hline 2017 & $187,516.77$ & $44,699.0$ \\
\hline 2018 & $202,883.60$ & $45,728.0$ \\
\hline
\end{tabular}

Sources: Author own research [INS, EUROSTAT, HG]

It can be observed from the study of the series of data under analysis, that during the considered period of time, the Gross Domestic Product registered a constant increase from year to year. Between 2000 and 2008 there was an increase of the Gross Domestic Product, with the difference from year to year. Thus, between 2008 and 2011, in the context of the economicfinancial crisis that has affected Romania too, since the second half of 2008, there are smaller differences between the values of the Real Gross Domestic Product of Romania from year to year, compared to the period 2004-2007, this fact being also observed from the following presentation (Figure 1): 


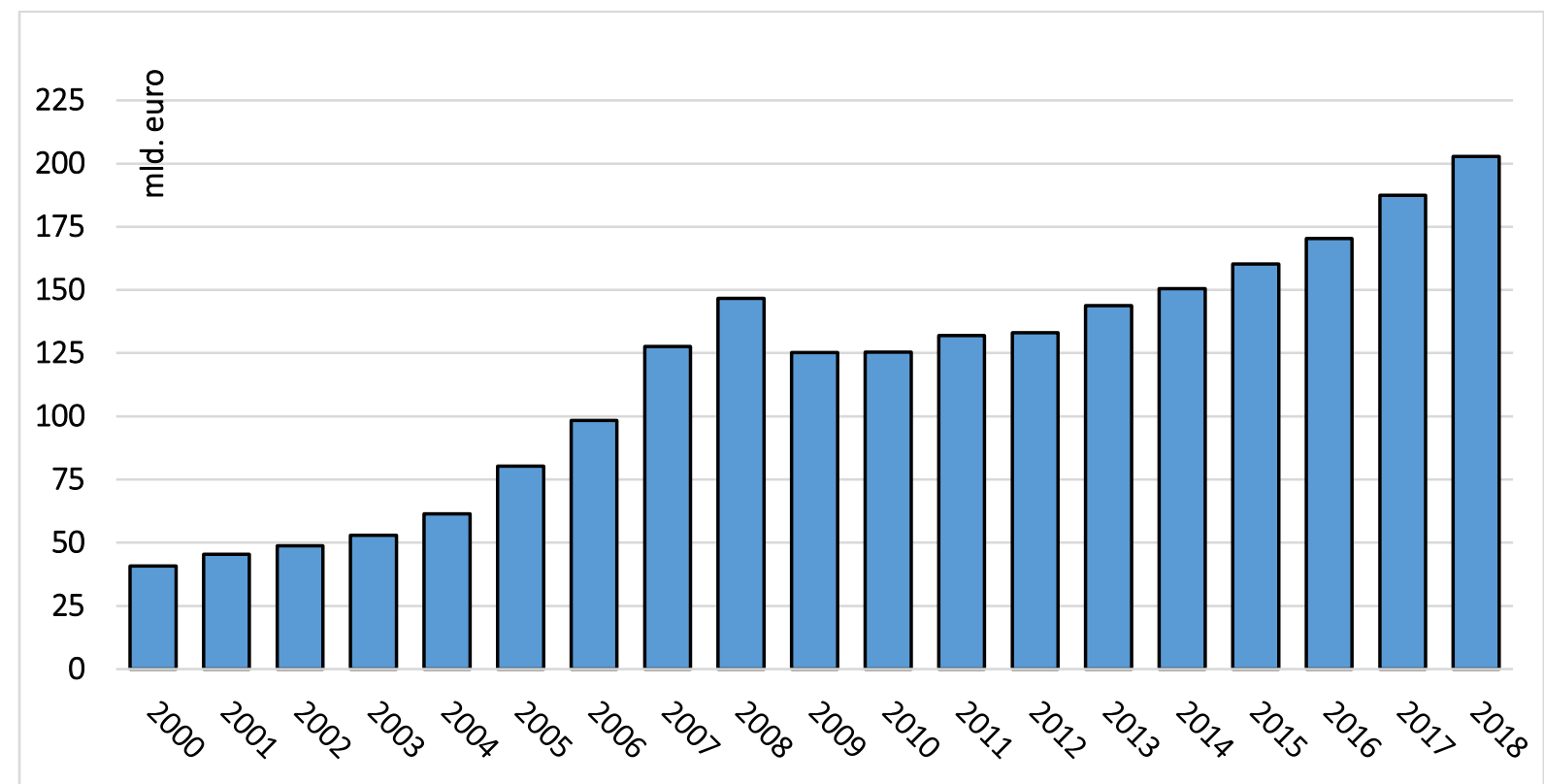

PICBE | 62

Figure 1. Evolution of Gross Domestic Product over the period 2000-2018

Source: Author's own processing based on the data in the Table1.

For the above period of time, the average of the indicator is about 117,545 millions of euro, with a variation between a minimum of 40,796 millions of euro (at the end of 2000) and a maximum of 202,883 millions of euro (at the end of 2018).

The same analysis was also performed regarding the evolution of the Final Electricity Consumption between 2000 - 2018, resulting that the indicator recorded an oscillating evolution from year to year, this fact being observed and from the following presentation (Figure 2):

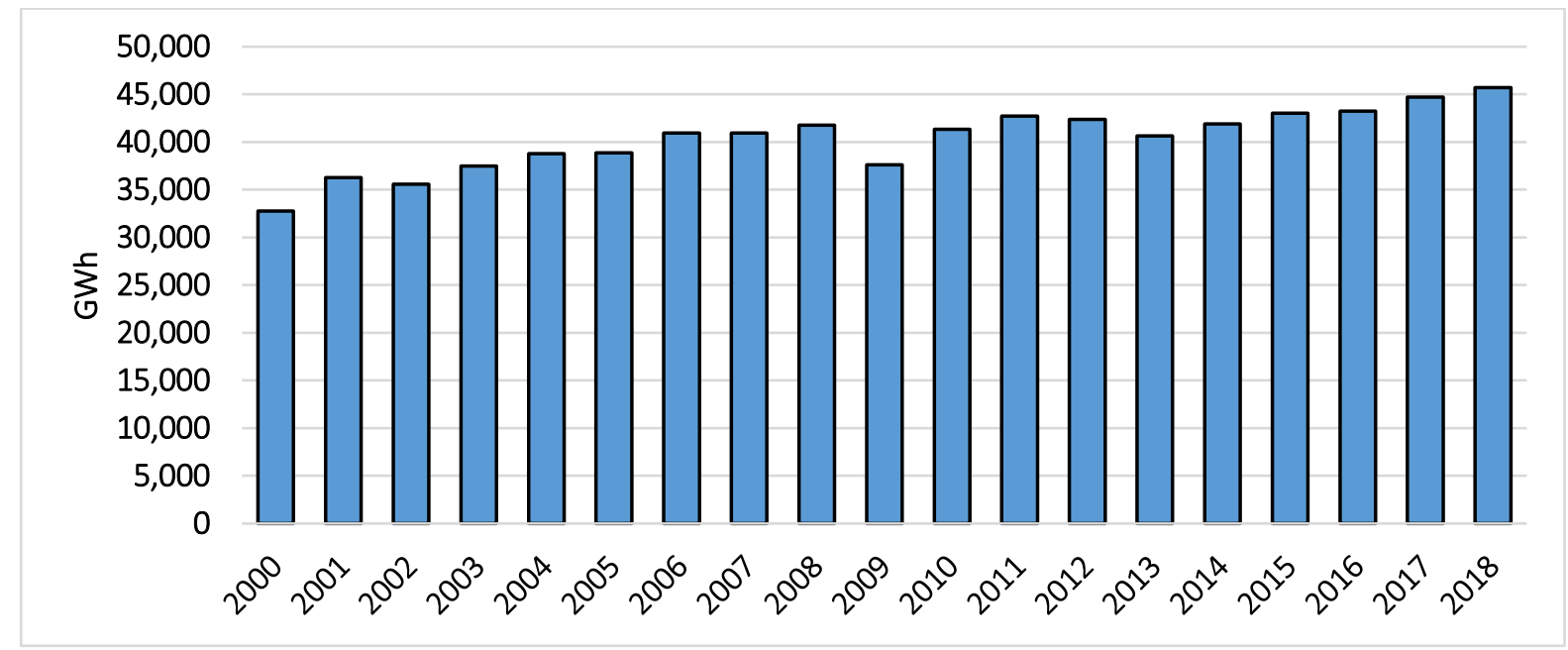

Figure 2. Evolution of the final consumption of electricity in the period 2000-2018

Source: Author's own processing based on the data in the Table1.

It can be observed that the evolution of the Final Electricity Consumption, during the period 2000-2018, has been oscillating from year to year, with the exception of 2009, when there was a major decrease compared to the previous year, as a result of the economic crisis. Thus, in 
this interval, it is noted that the value of this indicator decreases significantly compared to the immediately preceding time period, revealing also the small but steady growth from 2013-2018.

The indicator's range of variation shows that the value of the Final Electricity Consumption is between $32.753 \mathrm{GWh}$, in 2000 and $45.728 \mathrm{GWh}$, at the end of 2018, with an average value for the period 2000 - 2018, of $40.353 \mathrm{GWh}$.

From the two previous analysis, it was possible to draw a conclusion regarding on how to analyze the correlation between the two investigated indicators, Gross Domestic Product and Final Electricity Consumption. Thus, it is noted that the evolution of the two macroeconomic indicators is a similar one, with increases for the period 2000-2008 and a stagnation (with slight decrease) for the immediate next period, followed in the period 2013-2018 by a relatively small but constant growth.

Based on these findings, we can affirm that there is an interdependence between the value of the Gross Domestic Product and that of the Final Electricity Consumption.

Starting from data obtained for the Gross Domestic Product and the Final Electricity Consumption, it will be identify the existing relationship between the Final Electricity Consumption and the variation of the Gross Domestic Product, at the level of Romania. For this purpose, it was used a single-factor linear regression analysis, as a method of analysis, using the EViews 10 application.

\section{Results and discussions}

In order to specify the correct model, it was analysed the nature of series of data for Gross Domestic Product (GDP) and for the Final Electricity Consumption (CFEE).

\section{The nature of the series of data}

In order to test the stationarity of the time series we used ADF (Augmented Dickey - Fuller) from the EViews 10 application (Jula, D., Jula, N.M., 2019), obtaining the following:

The gross domestic product

Testing the stationarity of the series The Gross Domestic Product, at the level, the results showed that the risk that the series at the level would not be stationary is $93.4 \%$, well above the standard threshold of 5\%, following to test the stationarity of the series calculated in the first difference, establishing that the risk as the series in the first difference it is not stationary is $6.03 \%$, value above the standard 5\% threshold, but below the 10\% threshold.

In order to be on the safe side, the KPSS (Kwiatkowski-Phillips-Schmidt-Shin) test was applied, the results showing that the value of the LM type KPSS statistic is 0.103774 , lower than the critical value attached to the $10 \%$ threshold, which means that the test does not reject the hypothesis of stationarity for the series calculated in the first difference.

Effective unit root tests do not reject hypothesis I (1) at the $10 \%$ threshold - the $4 \mathrm{Ng}$ Perron type tests and the ERS (Elliott-Rothenberg-Stock Point-Optimal) test, respectively at the $1 \%$ threshold - the Elliott test - Rothenberg-Stock DF-GLS.

Therefore, we accept that the GDP series is non-stationary, integrated by order 1, being I (1).

Final consumption of electricity (CFEEE)

Testing the stationarity of the series Final consumption of electricity, at the level, the results showed that the risk that the series at the level would not be stationary is $28.08 \%$, much higher than the standard threshold of $5 \%$, to test the stationarity of the series calculated in the first difference, establishing that the risk that the series in the first difference is not stationary is less 
than $0.01 \%$. Therefore, we accept that the CFEE series is nonstationary, integrated by order 1 , ie I (1).

The KPSS test accepts the stationarity hypothesis of the first difference at a threshold above $10 \%$, and the efficient unit root tests do not reject hypothesis I (1) at the $10 \%$ threshold the $4 \mathrm{Ng}$-Perron tests and the ERS test (Elliott-Rothenberg-Stock Point-Optimal), respectively at the $1 \%$ threshold - Elliott-Rothenberg-Stock DF-GLS test.

PICBE | 64

\section{The econometric simple linear regression model}

In order to build a linear regression model, the Final Electricity Consumption was defined as the independent variable, while the Gross Domestic Product was considered a dependent (resultant) variable, taking into account that the series are I (1). Thus the regression model can be written in the form:

where:

$$
\mathrm{d}\left(\mathrm{PIB}_{\mathrm{t}}\right)=\mathrm{a}_{0}+\mathrm{a}_{1} \mathrm{~d}\left(\mathrm{CFEE}_{\mathrm{t}}\right)+\mathrm{e}_{\mathrm{t}}
$$

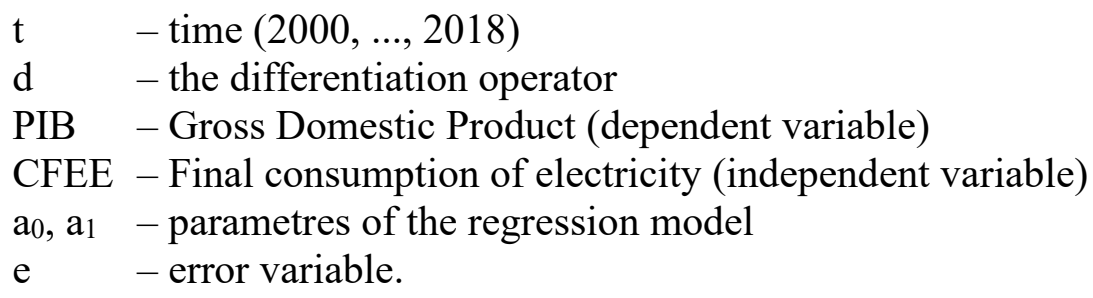

The essential problem of any regression model is the determination of the parameters of the model. In order to interpret the results obtained using the linear regression model, it is necessary to establish, from the beginning, whether it can be considered to be correct, or not.

In this context, there were entered data from the Table 1 into the EViews 10 application, resulting in the following (Table 2):

Table 2. The simple linear regression model between GDP dynamics and CFEE evolution

Dependent Variable: D(PIB)

Method: Least Squares

Sample (adjusted): 20012018

Included observations: 18 after adjustments

\begin{tabular}{lrlll}
\hline \multicolumn{1}{c}{ Variable } & Coefficient & Std. Error & t-Statistic & Prob. \\
\hline \multicolumn{1}{c}{ C } & 7559.330 & 2637.805 & 2.865766 & 0.0112 \\
D(CFEE) & 2.005310 & 1.378133 & 1.455091 & 0.1650 \\
\hline \hline R-squared & 0.116866 & Mean dependent var & 9004.824 \\
Adjusted R-squared & 0.061670 & S.D. dependent var & 10702.56 \\
S.E. of regression & 10367.30 & Akaike info criterion & 21.43514 \\
Sum squared resid & $1.72 \mathrm{E}+09$ & Schwarz criterion & 21.53407 \\
Log likelihood & -190.9163 & Hannan-Quinn criter. & 21.44878 \\
F-statistic & 2.117291 & Durbin-Watson stat & 1.181212 \\
Prob(F-statistic) & 0.164983 & & & \\
\hline \hline
\end{tabular}


The graphical results are shown in Figure 3. Although the hypothesis of the link between GDP dynamics and the evolution of CFEE is not rejected at the $10 \%$ threshold (concretely, $0.1650 / 2=0.0825$, ie $8.25 \%$ ), however, the errors are self-correcting and the probability that the model as a whole will be not significant is Prob (F-statistic) $=0.164983$, value above 5\% standard threshold. In these conditions, we do not continue with the application of the other tests, but we respect the model.

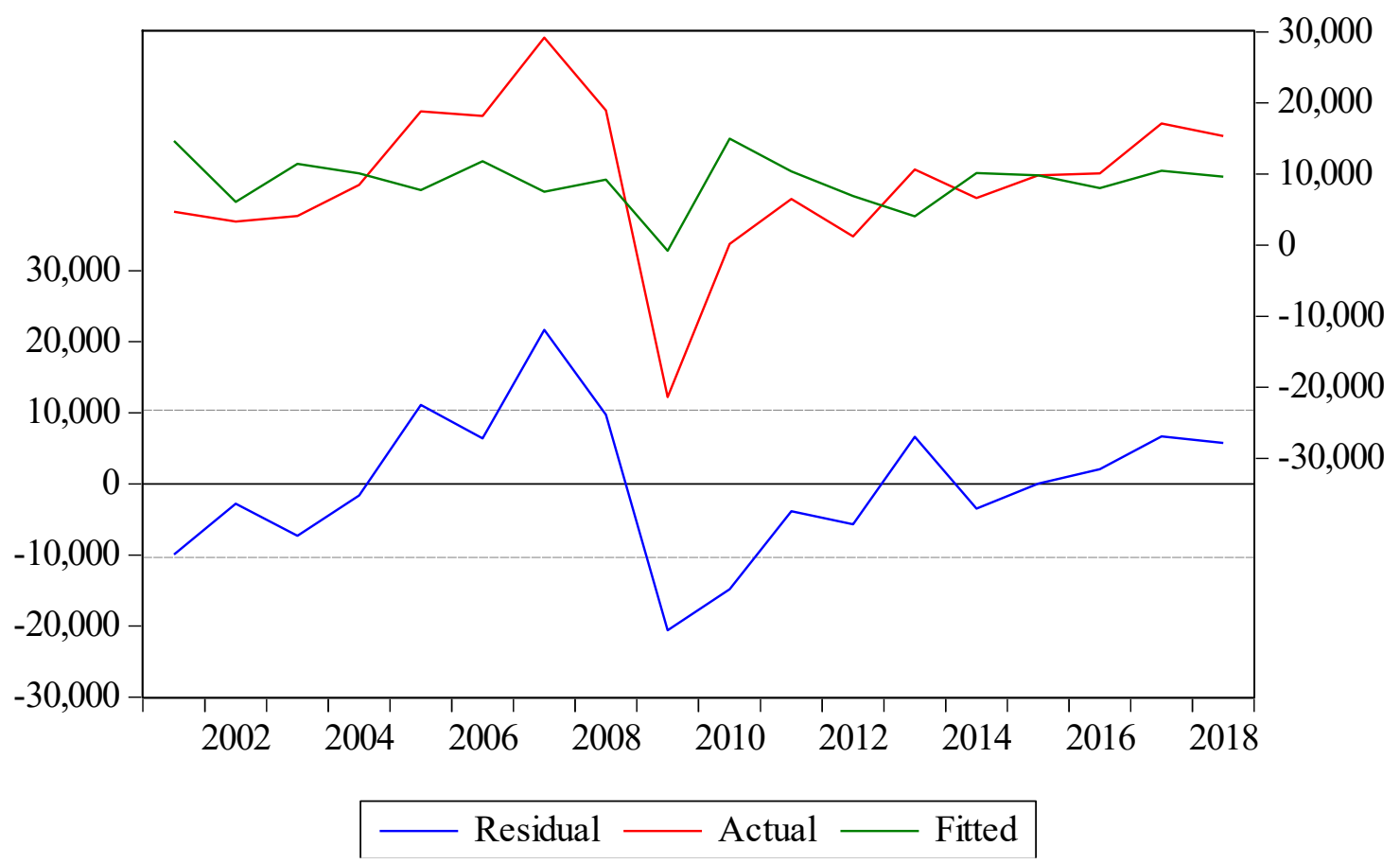

Figure 3. The simple linear regression model between GDP dynamics and CFEE evolution Source: calculations in EViews, based on the data in Table 1.

\section{The econometric model of squared linear regression}

Given the above results, the hypothesis of a more complex link between GDP and CFEE was tested, concretely, it was tested the hypothesis of a link as follows:

$$
\mathrm{d}\left(\mathrm{PIB}_{\mathrm{t}}\right)=\mathrm{a}_{0}+\mathrm{a}_{1} \mathrm{~d}\left(\mathrm{CFEE}_{\mathrm{t}}\right)+\mathrm{a}_{2} \mathrm{~d}\left(\mathrm{CFEE}_{\mathrm{t}}\right)^{2}+\mathrm{e}_{\mathrm{t}}
$$

where, similar with the above explained model,

t $\quad$ - time $(2000, \ldots, 2018)$

d - the differentiation operator

PIB - Gross Domestic Product (dependent variable)

CFEE - Final consumption of electricity (independent variable)

$a_{0}, a_{1}, a_{2}-$ parametres of the regression model

e - error variable. the Figure 4.

The results of estimating the squared linear regression are shown in the Table 3, and in

Table 3. The squared linear regression model between GDP dynamics and CFEE evolution

Dependent Variable: D(PIB)

Method: Least Squares 
Sample (adjusted): 20012018

Included observations: 18 after adjustments

\begin{tabular}{lrrrr}
\hline \multicolumn{1}{c}{ Variable } & Coefficient & Std. Error & t-Statistic & Prob. \\
\hline \hline C & 12711.38 & 2233.547 & 5.691119 & 0.0000 \\
D(CFEE) & 1.984914 & 0.970557 & 2.045129 & 0.0588 \\
D(CFEE)^2 & -0.001402 & 0.000338 & -4.154580 & 0.0008 \\
\hline \hline R-squared & 0.589374 & Mean dependent var & 9004.824 \\
Adjusted R-squared & 0.534624 & S.D. dependent var & 10702.56 \\
S.E. of regression & 7301.127 & Akaike info criterion & 20.78046 \\
Sum squared resid & $8.00 \mathrm{E}+08$ & Schwarz criterion & 20.92885 \\
Log likelihood & -184.0241 & Hannan-Quinn criter. & 20.80092 \\
F-statistic & 10.76480 & Durbin-Watson stat & 1.254798 \\
Prob(F-statistic) & 0.001261 & & & \\
\hline
\end{tabular}

Source: calculations in EViews, based on the data in Table 1.

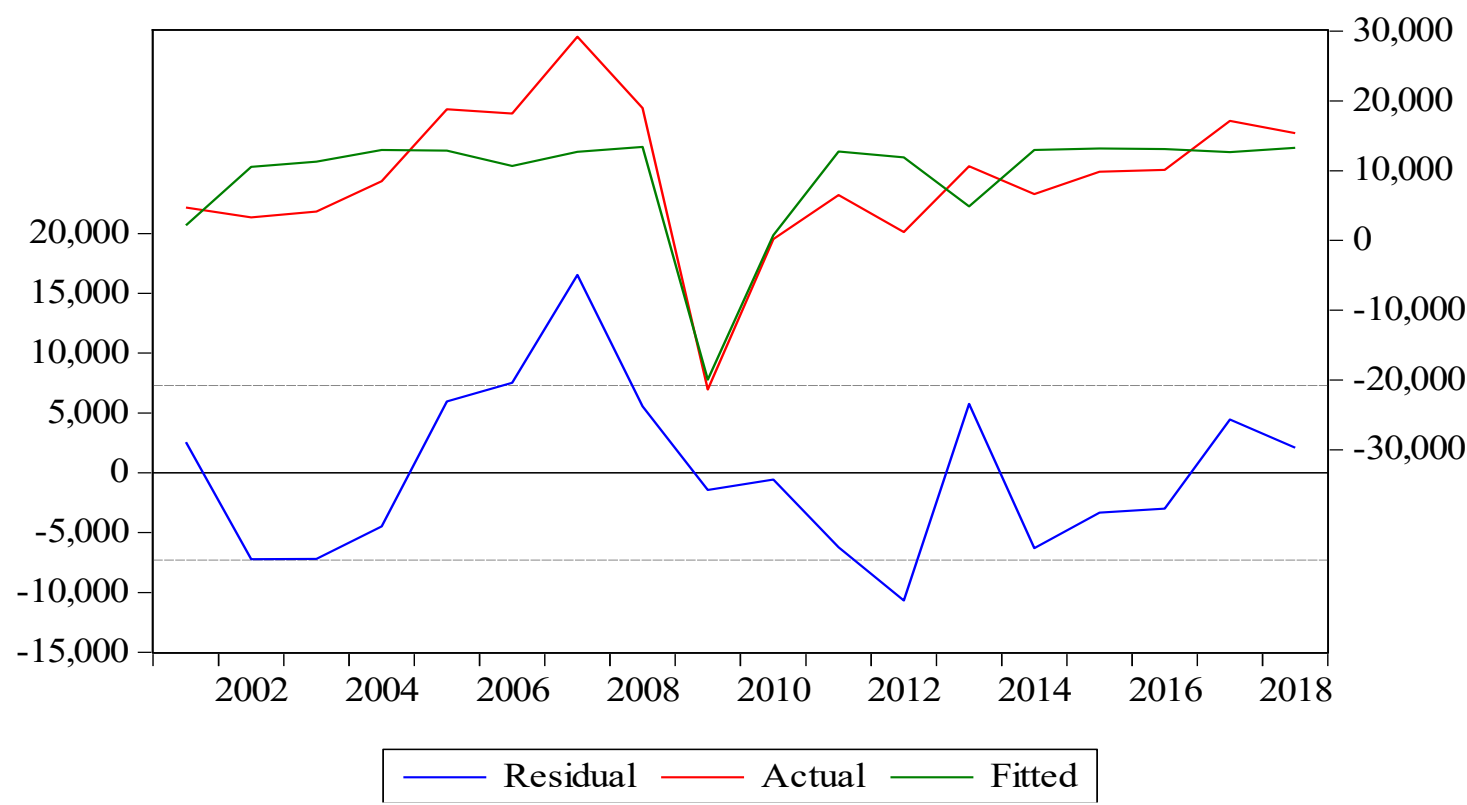

Figure 4. The squared linear regression model between GDP dynamics and CFEE evolution

Source: calculations in EViews, based on the data in Table 1.

The model is superior to the previous one, from the perspective of econometric performance. The risk that the estimators are not significant is below $5 \%$, and the risk that the model, as a whole, to be not significant is below 1\% (concretely, Prob (F-statistic) $=0.001261$ ). However, the graph shows a high residual value for the year 2007. Consequently, the model was respected by introducing a dummy variable for that year, the model being the following:

$$
\mathrm{d}\left(\mathrm{PIB}_{\mathrm{t}}\right)=\mathrm{a}_{0}+\mathrm{a}_{1} \mathrm{~d}\left(\mathrm{CFEE}_{\mathrm{t}}\right)+\mathrm{a}_{2} \mathrm{~d}\left(\mathrm{CFEE}_{\mathrm{t}}\right)^{2}+\mathrm{a}_{3} \mathrm{dum} 2007+\mathrm{e}_{\mathrm{t}},
$$


where the symbols have the meaning presented in the case of the previous model and dum2007 is the dummy variable, which is defined so that it has the value 1 for 2007 and 0 for the rest.

The econometric model of squared linear regression, assuming an atypical value in 2007

The results of the estimation of the squared linear regression model, assuming an atypical value in 2007, are presented in Table 4 and in Figure 5.

Table 4. The squared linear regression model between GDP dynamics and CFEE evolution, with the hypothesis of an atypical value in 2007

Dependent Variable: D(PIB)

Method: Least Squares

Sample (adjusted): 20012018

Included observations: 18 after adjustments

\begin{tabular}{lrlll}
\hline \hline \multicolumn{1}{c}{ Variable } & Coefficient & Std. Error & t-Statistic & Prob. \\
\hline \multicolumn{1}{c}{ C } & 10999.76 & 1916.581 & 5.739263 & 0.0001 \\
D(CFEE) & 2.224613 & 0.796977 & 2.791313 & 0.0144 \\
D(CFEE)^2 & -0.001259 & 0.000280 & -4.495819 & 0.0005 \\
@ISPERIOD("2007") & 18249.58 & 6265.026 & 2.912930 & 0.0113 \\
\hline \hline R-squared & 0.744331 & Mean dependent var & 9004.824 \\
Adjusted R-squared & 0.689545 & S.D. dependent var & 10702.56 \\
S.E. of regression & 5963.312 & Akaike info criterion & 20.41777 \\
Sum squared resid & $4.98 \mathrm{E}+08$ & Schwarz criterion & 20.61563 \\
Log likelihood & -179.7599 & Hannan-Quinn criter. & 20.44505 \\
F-statistic & 13.58608 & Durbin-Watson stat & 1.759237 \\
Prob(F-statistic) & 0.000198 & & & \\
\hline
\end{tabular}

Source: calculations in EViews, based on the data in Table 1. 


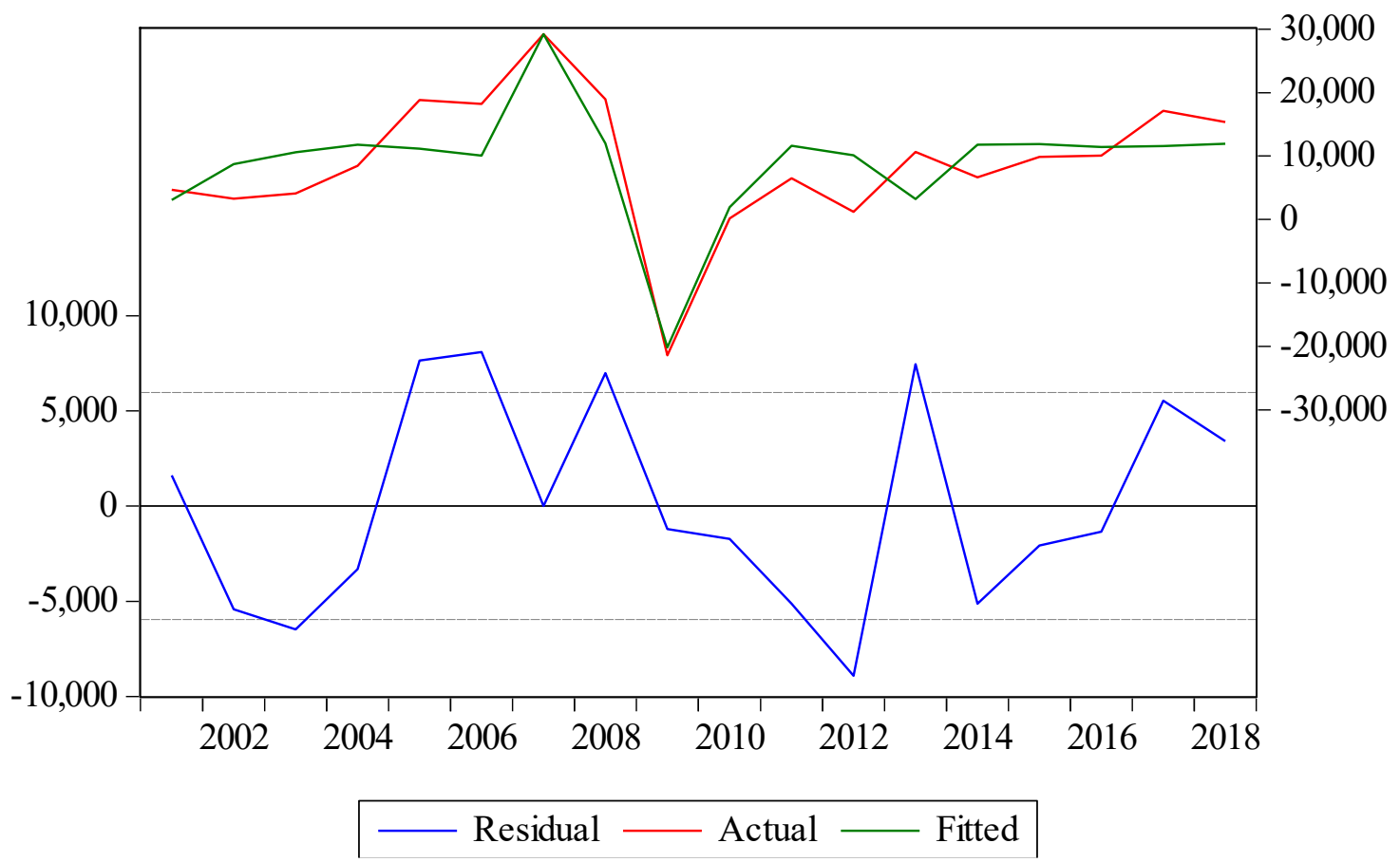

PICBE | 68

Figure 5. The squared linear regression model between GDP dynamics and CFEE evolution, with the hypothesis of an atypical value in 2007

Source: calculations in EViews, based on the data in Table 1.

The risk that the estimators are not significant is below 5\%, and the risk that the model, as a whole, to be not significant is below 1\% (concretely, Prob (F-statistic) $=0.000198)$. The errors do not present the 1st order autocorrelation phenomenon: the value of Durbin-Watson statistics is $\mathrm{dw}=1.759$, given that the threshold of theoretical statistics is 1.69 , for $\mathrm{n}=18$ and $\mathrm{k}=3$. This means that

$$
\mathrm{d}_{\mathrm{u}}=1.69 \leq \mathrm{d}_{\mathrm{w}}=1.759 \leq 4-\mathrm{d}_{\mathrm{u}}=2.31
$$

For the higher order autocorrelation, the Lagus type Breusch-Godfrey test was applied, resulting that the probability attached to the independence hypothesis of errors (nonautocorrelating) is $86.89 \%$, which means that we accept the non-correlation hypothesis, at least up to order 2 (testing for a higher order leads to similar results, but the number of degrees of freedom is small).

For heteroscedasticity, the White test was applied (Jula, D., Jula, N.M., 2019), showing that the probability attached to the null hypothesis (errors are not heteroscedastic) is 19.95\%, higher than the standard 5\% threshold, which means that we accept the hypothesis of lack of heteroscedasticity.

For the normality of the error distribution we apply the Jarque-Bera test (Jula, D., Jula, N.M., 2019). The results are as follows (Figure 6): 


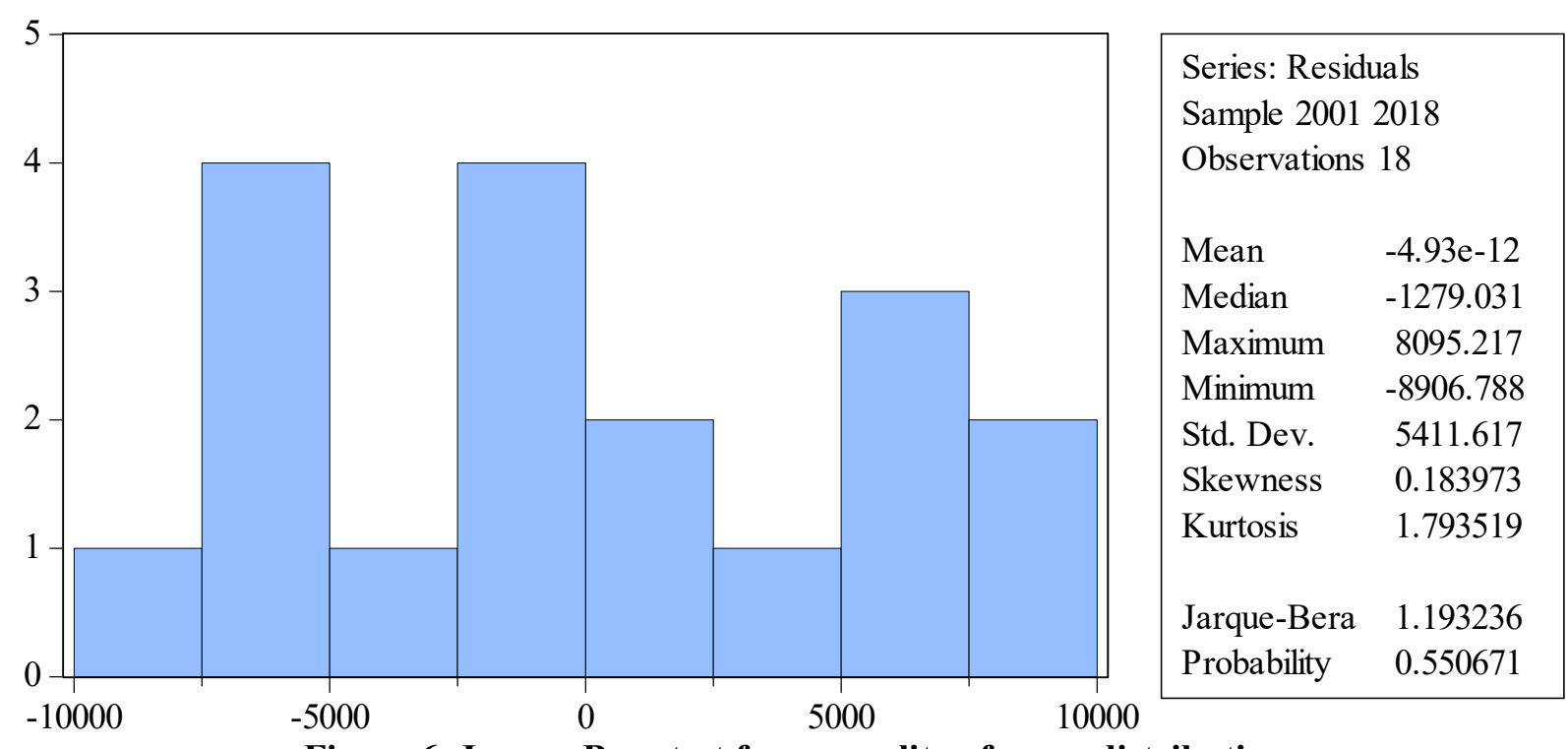

Figure 6. Jarque-Bera test for normality of error distribution

Source: calculations in EViews, based on the data in Table 1.

The value of the Jarque-Bera test is $\mathrm{JB}=1.1932$, lower than the threshold in the $\chi^{2}$ distribution with 2 degrees of freedom, for the 5\% threshold, ie 5,991. Specifically, the risk of errors not being normally distributed is $55,067 \%$. Under these conditions, the normality of the error distribution is accepted.

Given the test results, we consider the model

$$
\begin{gathered}
\mathrm{d}\left(\mathrm{PIB}_{\mathrm{t}}\right)=10999.764216+2.224613 * \mathrm{~d}\left(\mathrm{CFEE}_{\mathrm{t}}\right)- \\
-0.001259 * \mathrm{D}\left(\mathrm{CFEE}_{\mathrm{t}}\right)^{2}+18249.581891 * @ \operatorname{ISPERIOD}(" 2007 ")
\end{gathered}
$$

properly assesses the link between GDP dynamics and the evolution of CFEE.

\section{Kuznets-type relationship between final energy consumption and gross domestic product}

The squared equation that it has been analyzed suggests the existence of a Kuznets-type relationship between final electricity consumption and economic dynamics.

The model built is of the type:

$$
\mathrm{d}\left(\mathrm{CFEE}_{\mathrm{t}}\right)=\mathrm{a}_{0}+\mathrm{a}_{1} \mathrm{~d}\left(\mathrm{PIB}_{\mathrm{t}}\right)+\mathrm{a}_{2} \mathrm{~d}\left(\mathrm{PIB}_{\mathrm{t}}\right)^{2}+\mathrm{e}_{\mathrm{t}}
$$

where, similar with the above explained model,

$\mathrm{t} \quad$ - time $(2000, \ldots, 2018)$

d - the differentiation operator

PIB - Gross Domestic Product (dependent variable)

CFEE - Final consumption of electricity (independent variable)

$\mathrm{a}_{0}, \mathrm{a}_{1}, \mathrm{a}_{2}$ - parametres of the regression model

e $\quad$ error variable.

If between the variables there is a Kuznets type relation, then a $<0$, the interpretation being in the sense that the relation is concave with respect to the origin, so that the economy's 
intensity increases as economic growth reaches a certain threshold. After that threshold, economic growth is associated with the relative decrease in energy consumption.

The results are as follows (Table 5):

Table 5. Kuznets-type relationship between final energy consumption and gross domestic product

Dependent Variable: D(CFEE)

PICBE $\mid 70$

Method: Least Squares

Sample (adjusted): 20012018

Included observations: 18 after adjustments

\begin{tabular}{lrrll}
\hline \hline Variable & Coefficient & Std. Error & t-Statistic & Prob. \\
\hline \multicolumn{1}{c}{ C } & 744.8127 & 500.1549 & 1.489164 & 0.1572 \\
D(PIB) & 0.102547 & 0.036991 & 2.772223 & 0.0142 \\
D(PIB)^2 & $-5.01 E-06$ & $1.78 \mathrm{E}-06$ & -2.811830 & 0.0131 \\
\hline \hline R-squared & 0.421689 & Mean dependent var & 720.8333 \\
Adjusted R-squared & 0.344581 & S.D. dependent var & 1824.526 \\
S.E. of regression & 1477.099 & Akaike info criterion & 17.58456 \\
Sum squared resid & 32727317 & Schwarz criterion & 17.73295 \\
Log likelihood & -155.2610 & Hannan-Quinn criter. & 17.60502 \\
F-statistic & 5.468803 & Durbin-Watson stat & 2.063243 \\
Prob(F-statistic) & 0.016452 & & & \\
\hline
\end{tabular}

Source: calculations in EViews, based on the data in Table 1.

In the presented estimation, the coefficient $\mathrm{a}_{0}$ is not significantly different from zero, at the standard threshold of $5 \%$ (the risk is $0.1572 / 2=0.0736$ ), the following model being estimated without a free time:

$$
\mathrm{d}\left(\mathrm{CFEE}_{\mathrm{t}}\right)=\mathrm{a}_{1} \mathrm{~d}\left(\mathrm{PIB}_{\mathrm{t}}\right)+\mathrm{a}_{2} \mathrm{~d}\left(\mathrm{PIB}_{\mathrm{t}}\right)^{2}+\mathrm{e}_{\mathrm{t}}
$$

The results are, as follows:

Table 6. The Kuznets type relationship, without a free element, between the final energy consumption and the gross domestic product

Dependent Variable: D(CFEE)

Method: Least Squares

Sample (adjusted): 20012018

Included observations: 18 after adjustments

\begin{tabular}{crrrc}
\hline \hline Variable & Coefficient & Std. Error & t-Statistic & Prob. \\
\hline \hline $\mathrm{D}(\mathrm{PIB})$ & 0.123439 & 0.035506 & 3.476612 & 0.0031 \\
$\mathrm{D}(\mathrm{PIB})^{\wedge} 2$ & $-3.97 \mathrm{E}-06$ & $1.70 \mathrm{E}-06$ & -2.335572 & 0.0329 \\
\hline \hline R-squared & 0.336191 & Mean dependent var & 720.8333
\end{tabular}




\begin{tabular}{lrll} 
Adjusted R-squared & 0.294703 & S.D. dependent var & 1824.526 \\
S.E. of regression & 1532.273 & Akaike info criterion & 17.61133 \\
Sum squared resid & 37565744 & Schwarz criterion & 17.71026 \\
Log likelihood & -156.5020 & Hannan-Quinn criter. & 17.62497 \\
Durbin-Watson stat & 1.915291 & & \\
\hline
\end{tabular}

PICBE $\mid 71$

Source: calculations in EViews, based on the data in Table 1.

The coefficients are significantly different from zero, and the errors are not autocorrelated with step $1(\mathrm{dw}=1.915)$.

For the higher-order autocorrelation, the Lagus Breusch-Godfrey test was applied, resulting in the assumption that the errors are autocorrelated, the error risk is $91.36 \%$, well above the $5 \%$ threshold.

For heteroscedasticity, the White test was applied, resulting in the assumption that the errors are heteroscedastic, the error risk is $35.42 \%$, well above the $5 \%$ threshold.

For the normality of the error distribution we apply the Jarque-Bera test. The results are as follows (Figure 7):

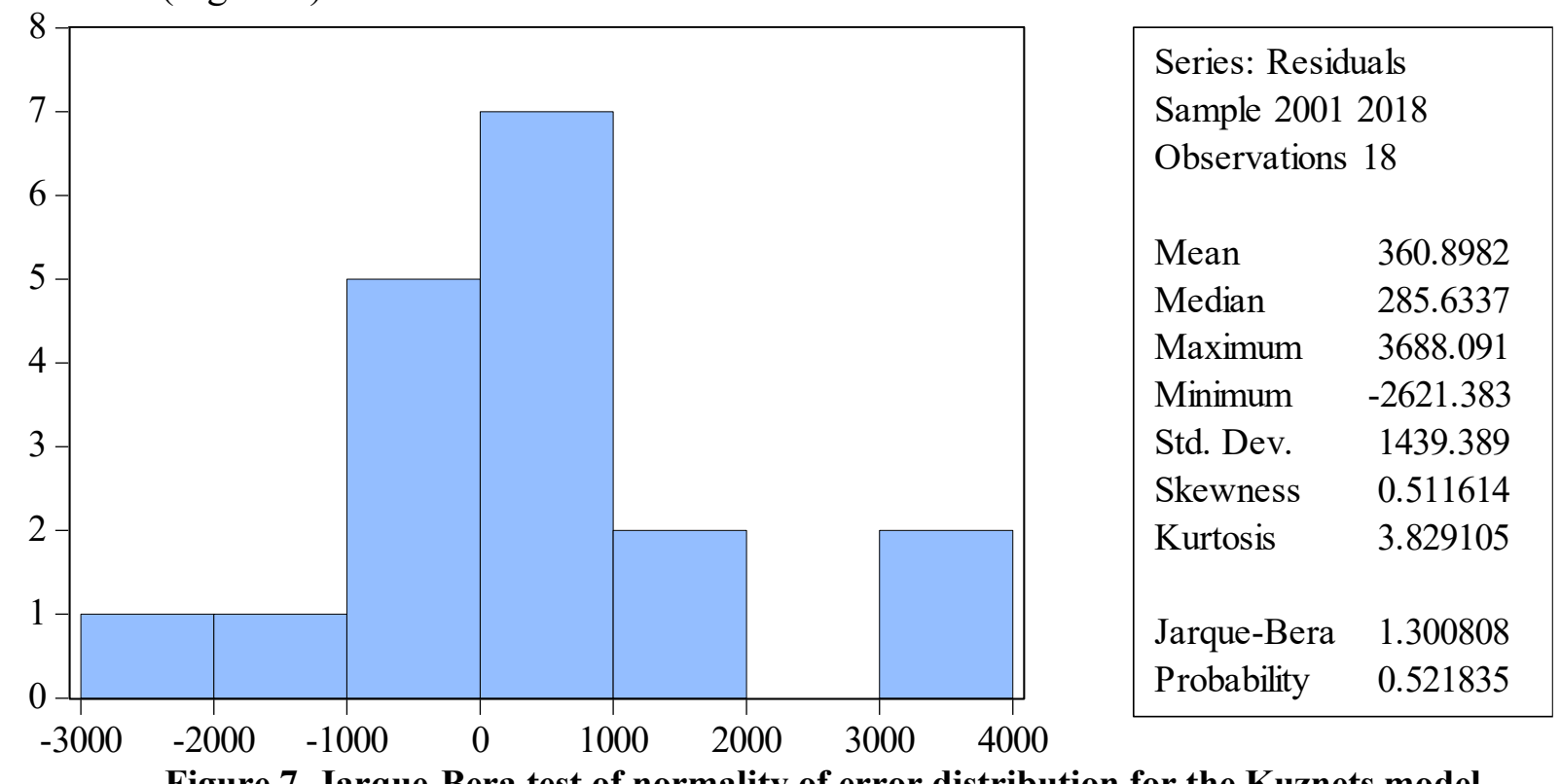

Figure 7. Jarque-Bera test of normality of error distribution for the Kuznets model

Source: calculations in EViews, based on the data in Table 1.

The value of the Jarque-Bera test is $\mathrm{JB}=1.3008$, lower than the threshold in the $\chi^{2}$ distribution with 2 degrees of freedom, for the 5\% threshold, ie 5,991. Specifically, the risk of errors not being normally distributed is $52,184 \%$. Under these conditions, we accept the normality assumption of error distribution.

Given the test results, we consider the model

$$
\mathrm{d}\left(\mathrm{CFEE}_{\mathrm{t}}\right)=0.123439 * \mathrm{D}\left(\mathrm{PIB}_{\mathrm{t}}\right)-3.971144 \mathrm{e}-06 * \mathrm{D}\left(\mathrm{PIB}_{\mathrm{t}}\right)^{2}+\mathrm{u}_{\mathrm{t}} \text {, }
$$

evaluates the Kuznets-type link between the evolution of CFEE and the dynamics of GDP. The estimator of parameter $\mathrm{a}_{2}$ has the anticipated negative sign $(\hat{\mathrm{a}} 2=-3.97 \cdot 10-6)$, so that the relation is concave with respect to the origin, so that the economy's intensity increases as economic 
growth reaches a certain threshold. After that threshold, economic growth is associated with the relative decrease in energy consumption.

\section{Conclusions}

Romania is among the countries with an energy intensity of the gross domestic product 2-3 times higher, compared to the levels recorded by this indicator in the developed countries. This underperformance is caused, to a greater extent, by the non-application of modern technologies that use a low energy level, to which are added the losses on the transportation/distribution network and the technological gap that separates the Romanian producers from those of the developed countries.

The causes of this macroeconomic energy efficiency gap between Romania and the developed EU country members, do not reside exclusively in the poor performances of the Romanian energy producers, due to the low technological level of the production capacities, the tools and the equipments.

The causes of this macroeconomic energy efficiency gap between Romania and the developed member countries of the EU, do not reside exclusively in the poor performances of the Romanian energy producers, due to the low level of the production capacities, the equipment and the equipment.

It must be taken into account that the energy intensity in the national economy is a macroeconomic parameter that depends on the structure of the national economy and becomes a technical parameter, only on a secondary level, that characterizes the energy use efficiency.

On the other hand, it is necessary to solve the problem of the huge energy losses in the transportation and distribution network to which the intermediaries should bring a significant contribution. Therefore, Romania must put into operation the new and competitive energy capacities by using the clean technologies.

Following the tests carried out on the two choosen variables, the Gross Domestic Product of Romania and the Final Consumption of Electricity I may sustain that the energy intensity of the economy increases as economic growth reaches a certain threshold. After that threshold, economic growth is associated with a relative decrease in energy consumption. So, the decoupling of the two indicators is mainly influenced by both the energy efficiency level and the new structure of the national economy.

The current analysis cannot be considered complete without mentioning the important value of the free term in the model between GDP dynamics and the evolution of CFEE. This value means that those factors that were not included in the model have a high influence on the Gross Domestic Product.

Starting from the importance of the free term, considering that its high value means that the factors that were not included in the model have a high influence on the Gross Domestic Product, it is necessary to continue the analysis by identifying new indicators (independent variables) in order to analyze the correlation between GDP and those new indicators.

\section{References}

Bratianu, C., \& Vatamanescu, E.M. (2017). Students' perception on developing conceptual generic skills for business: a knowledge-based approach. VINE Journal of Information and Knowledge Management Systems, 47(4), 490-505. 
Dima, A.M., Meghișan-Toma, G.M. (2018) Reserch on implementing education for sustainable development. Proceedings of the international conference on business excellence. Vol 12, No $1,300-310$.

Dobrescu, E. (2002).Tranziția în România. Abordări econometrice, Editura Economică, 369

Jula, D., Jula, N. M. (2018). Econometrie, Bucureşti, Editura Mustang, 154, 116-119

Jula, D., Jula, N. M. (2019). Econometria seriilor de timp, Bucureşti, Editura Mustang, 118-123

Lau, E., Chye, X. H., Choong, C. K. (2012). Energy-Growth causality: A panel analysis. Journal of European Economy, 11(2012), 218-230.

Lee, C.C. (2005). Energy consumption and GDP in developing countries: a cointegrated panel analysis. Energy Economics, 27(2005), 415-427

Pîrlogea, C., Ciucea, C. (2011). Obtaining economic growth from energy consumption in urban areas. Theoretical and Empirical Researches in Urban Management, 6(2011), 73-83

Stjepanović, S. (2018). Relationship between energz consumption and economic growth in 30 countries in Europe - panel, Ekonomski pregled, Vol. 69 (2018), 43-57.

BP - Statistical Review of World Energy - 2018. Available at: www.bp.com/content/dam/bp/business-sites/en/global/corporate/pdfs/energyeconomics/statistical-review/bp-stats-review-2018-renewable-energy.pdf

Eurostat - cod: tec0001. Available at: https://ec.europa.eu/eurostat/tgm/refreshTableAction.do?tab=table\&plugin=1\&pcode=tec $00001 \&$ language $=$ en

Eurostat - Energy intensity cod: nrg_ind_ei. Available at: http://appsso.eurostat.ec.europa.eu/nui/show.do?dataset=nrg_ind_ei\&lang=en

Government Decision no. 203/1999 regarding the approval of the National Action Plan in the field of energy efficiency IV, (Table 1.15)

Government Decision no. 122/2015 regarding the approval of the National Action Plan in the field of energy efficiency III, (Table 1.17)

Institutul Național de Statistică - Balanța energetică și structura utilajului energetic. Available at: http://www.insse.ro/cms/ro/tags/balanta-energetica-si-structura-utilajului-energetic

Ministry of Energy - National Energy Strategy - Analysis of the current state - February 2016,17. Available at: http://energie.gov.ro/wp-content/uploads/2016/03/Actualizare-Analizasistem_draft-final_19-feb-2016-1.pdf

Tantau, A., \& Gavrilescu, I. (2019). Key anxiety factors for buying an electric vehicle. Management \& Marketing - Challenges for the Knowledge Society, 14(2), 240-248.

Transelectrica - Cerinte privind transparenta informatiilor referitoare la Consumul de Energie Electrica. Available at: http://transelectrica.ro/web/tel/consum - Table 5

UNEP (2011) Decoupling natural resource use and environmental impacts from economic growth, A Report of the Working Group on Decoupling to the International Resource Panel. Available at: http://wedocs.unep.org/handle/20.500.11822/9816 